\title{
DECENTRALIZED STABILIZATION AND CONTROL STRATEGIES FOR INTERCONNECTED POWER SYSTEMS
}

\author{
by \\ Dr. ATEIA A. ABDELMAGEED \\ - GENERAL DIRECTOR OF ELECTRIC MOTORS MANUFACTURE \\ - SHOUBRA COMPANY FOR ENGINEERING INDUSTRIES \\ - NATIONAL ORGANIZATION FOR MILITARY PRODUCTION
}

\section{ABSTRACT}

The paper considers the problem of stabilizing and control of a linear lime invariant multivariable system, representing power system dynamics, using two techniques: The first technique adopts the decentralized stabilization approach, while the second depends upon the decomposition coordination approach. Both techniques are applied to an interconnected power system consisting of three synchronous machines. The simulation results proved the capability of both techniques in stabilization and control of the system under consideration.

\section{INTRODUCTION}

Economics in system design are achieved with large unit sizes, higher per unit reactance for generating and transmission equipment designs. These modern trends however reduce the dynamic stability of synchronous machines so that the phenomenon of their stability under small perturbations has received a great deal of attention. Previous work has been devoted to a study of the optimal control of multimachine power systems. This is done by controlling all the machines by one optimal controller called centralized controlle $[1-3,7]$. However due to the exponential rise in power system interconnections, this centralized control is practically undesirable for large power systems due to : 
1) Computational difficulties encountered in solving a single Riccati equation of large order.

2) High costs of the communication system need for transmitting all the state variables to the centralized controller.

3) The stability of the system may be lost if a fault occurs in the communication system.

The above difficulties can be alleviated by decomposing the original problem into several subproblems, which are much easier to solve. In the first part of this paper, a decentralized stabilization technique [8-10] is presented and examined through its application to an interconnected power system. The second part of this paper focuses on elaborating of decentralized control using decomposition-coordination technique. The later one is also examined by applying the elaborated control to the same system. The second technique is characterized by its simplicity of algorithn and its applicability for practical implementation.

\section{POWER SYSTEM MODEL DESCRIPTION}

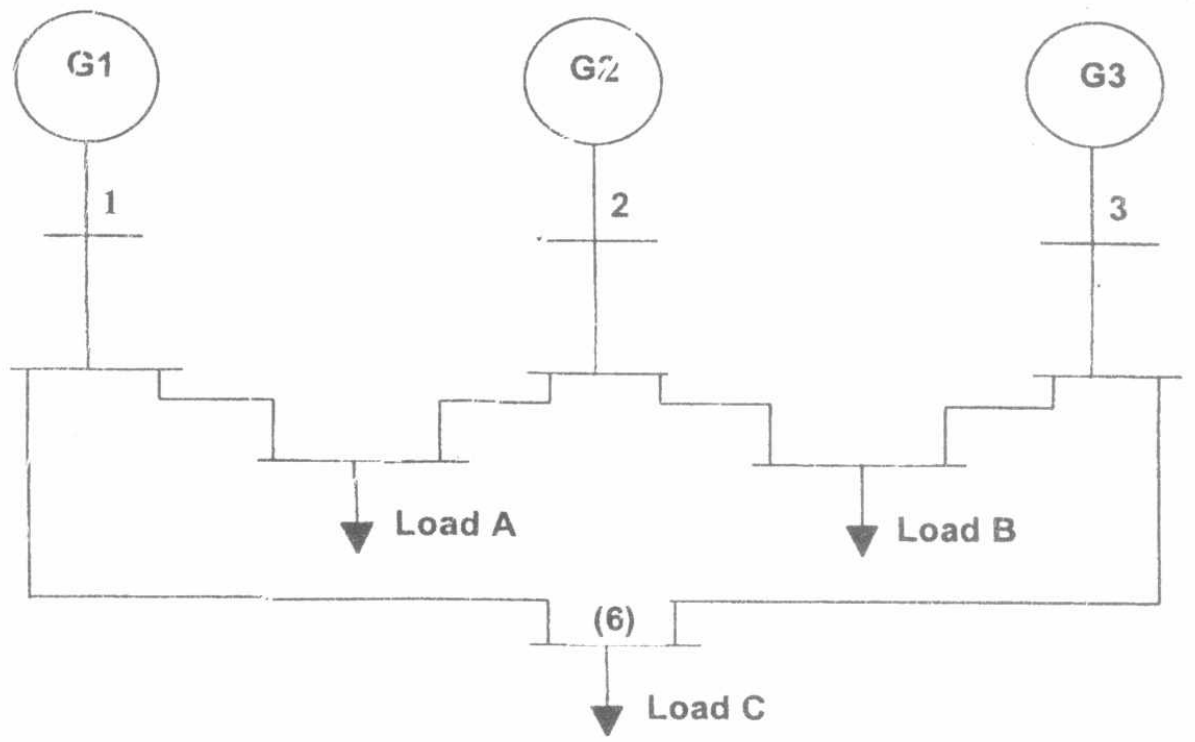

Figure (1)

Figure (1) shows the configuration of an interconnected power system, ea'sh subsystem is assumed to have one synchronous machine. This is used as a.n example in this styudy. The details of this system is found in appendix (1). 
In [2], it is shown that the dynamics of the interconnected power system of Figure (1) may be described by the following state equation (for small disturbances about a given operating point).

$$
\begin{aligned}
& \dot{x}(t)=\hat{A} \cdot x(t)+B \cdot u(t) \\
& x\left(t_{0}\right)=x_{0}
\end{aligned}
$$

Where :

$x(t)$ is an n-dimensional composite state vector, $\mathrm{u}(\mathrm{t})$ is an m-dimensional composite control vector, and $\mathrm{A}$ and $\mathrm{B}$ are constant matrices of dimensions $\mathrm{n} \mathrm{x} \mathrm{n}$ and $\mathrm{n} \mathrm{x} \mathrm{m}$ respectively.

This composite system, $\mathrm{S}$, may be described as an interconnection of $\mathrm{N}$ subsystems $\mathrm{S}_{1}, \mathrm{~S}_{2}, \ldots \mathrm{S}_{\mathrm{N}}[3]$.

$$
\dot{x}(t)=[A+H] \cdot x(t)+B \cdot u(t)
$$

Where :

$$
\begin{aligned}
& x^{T}=\left[\begin{array}{llll}
x_{1}^{T} & x_{2}^{T} & \ldots & x_{n}^{T}
\end{array}\right] \quad u^{T}=\left[\begin{array}{llll}
u_{1}^{T} & u_{2}^{T} & \ldots & u_{n}^{T}
\end{array}\right] \quad \text { and } \\
& A=A+H
\end{aligned}
$$

For subsystem $S_{i}, x_{i}(t)$ is an $n_{i}$-dimensional state vector with $n=\sum_{i=1}^{N} n_{i}$ and $U_{i}(t)$ is an $m_{i}$-dimensional vector with $m=\sum_{i=1}^{N} m_{i}$. Also, $A=$ block diagonal $\left[A_{1}, A_{2}, \ldots A_{N}\right]$, $\mathrm{B}=$ block diagonal $\left[\mathrm{B}_{1}, \mathrm{~B}_{2}, \ldots \mathrm{B}_{\mathrm{N}}\right]$, and 


$$
H=\left[\begin{array}{cccc}
0 & A_{12} & \cdots & A_{1 n} \\
A_{21} & 0 & \cdots & A_{2 n} \\
\cdots & \cdots & \cdots & \cdots \\
A_{n 1} & A_{n 2} & \cdots & 0
\end{array}\right]=\left[\begin{array}{c}
\mathrm{H}_{1} \\
\mathrm{H}_{2} \\
\cdots \\
\mathrm{H}_{n}
\end{array}\right]
$$

is the interconnection matrix. Where $A_{i}, A_{i j}$, and $B_{i}$ are $n_{i} \times n_{i}, n_{i} \times n_{j}$, and $n_{i}$ $\mathrm{x} \mathrm{m}_{\mathrm{j}}$ constant matrices, All pairs $\left(\mathrm{A}_{\mathrm{i}}\right.$, and $\left.\mathrm{B}_{\mathrm{i}}\right)$ are assumed controllable. All matrices $B_{i}$ are assumed to be of full rank $m_{j}$.

Associated with each subsystem $S_{i}$ is a performance index $J_{i}$ of the form :

$$
J_{i}=\frac{1}{2} \int_{0}^{\infty}\left(x_{i}^{T} Q_{i} x_{i}+u_{i}^{T} R_{i} u_{i}\right) d t
$$

Where $Q_{i}$ is an $n_{i} \times n_{j}$ positive semidefinite matrix and $R_{i}$ is an $m_{i} \times m_{j}$ positive definite matrix.

The problem is how to find the $u_{\mathrm{i}}(i=1,2, \ldots, \mathrm{n})$ which minimize $\mathrm{J}_{\mathrm{i}}$ and guarantee the stability of the overall system $\mathrm{S}$.

\section{DECENTRALIZED STABILIZATION STRATEGY}

Our objective is find the $U_{i}$ of the form :

$U_{i}=-K_{i} X_{i}, i=1,2, \ldots, N$.

Which minimize equation (3) and guarantee the stability of the overall systern $\mathrm{S}$ given by:

$\dot{y}_{i}(t)=[A+H-B K] \cdot x(t)$

With $\mathrm{K}=$ block diagonal $\left[\mathrm{K}_{\mathrm{i}}, \mathrm{K}_{2}, \ldots \mathrm{K}_{\mathrm{N}}\right]$. This is given in literature [3].

The regulators of equation (4) are called static controllers. The necessary condition for stabilization by local static regulators is that the decentralized fixed modes to be stable. These modes are the eigen-values of 
the closed loop matrix (5) that are common with the eigen-values of $\mathrm{A}$ for any matrix K [4]. However, this condition is in factnecessary and sufficient for stabilization by local dynamic controller [4].

Sufficient conditions for solving this problem using lnoal static controllers is derived [4], consider the decoupled subsyste $n s S_{1}, S_{2}, \ldots S_{N}$ in which the interaction matrix $\mathrm{H}$ is assumed, for a while, to be zero and described by :

$$
\dot{x}(t)=A \cdot x(t)+\sum B_{i} \cdot l_{i}(t), i=1,2, \ldots, N
$$

Also, the notion of exponential stability is adopted [5] for the isolated subsystems of equation (6). i.e., the solution of equation (6) should satisfy $\mathrm{x}_{\mathrm{i}} \mathrm{e}^{\alpha \mathrm{t}} \rightarrow 0$ as $\mathrm{t} \rightarrow \infty$ where $\alpha>0$. In other words, the closed loop system poles will be to the left of $\operatorname{Re}(\mathrm{s})=-\alpha$.

In this case, the system will be exponentially st:ible with degree $\alpha$. Each subsystem $\mathrm{S}_{\mathrm{i}}(\mathrm{I}=1,2, \ldots, \mathrm{N})$ described by equation (6) can be exponentially stabilized with degree $\alpha$ and minimizes :

$J_{i}=\frac{1}{2} \int_{0}^{\infty}\left(x_{i}^{T} Q_{i} x_{i}+u_{i}^{T} R_{i} u_{i}\right) e^{2 \alpha}=d t$

When the control vectors are given by :

$\mathrm{u}_{\mathrm{i}}=-\mathrm{R}_{\mathrm{i}}{ }^{-1} \mathrm{~B}_{\mathrm{i}}{ }^{\mathrm{T}} \mathrm{P}_{\mathrm{i}} \mathrm{X}_{\mathrm{i}}, \mathrm{i}=1,2, \ldots, \mathrm{N}$ (8)

Where $\mathrm{P}_{i}$ is the symmetric positive definite solution of the algebraic matrix Riccati equation:

$\mathrm{P}_{i}\left(\mathrm{~A}_{i}+\alpha I\right)+\left(\mathrm{A}_{i}+\alpha I\right)^{\mathrm{T}} \mathrm{E}_{2}+\mathrm{Q}_{i}-\mathrm{F}_{i} \mathrm{~B}_{i} \mathrm{E}_{i}{ }^{-1} \mathrm{~B}_{i}{ }^{\mathrm{T}} \mathrm{P}_{i}=0$

Using the control $u_{i}$ of equation (8), the composite system represerited by equation (2) is described by : 


$$
\dot{x}(t)=\left[A-B R^{-1} B^{T} P+H\right] \cdot x(t)
$$

Where $\mathrm{R}^{-1}=$ block diagonal $\left[\mathrm{R}_{\mathrm{i}}^{-1}\right], \mathrm{P}=\operatorname{block}$ diagonal $\left[\mathrm{Q}_{\mathrm{i}}\right],(\mathrm{I}=1,2, \ldots$, $N)$. The response of the interaction will change the stability, and it is needed to obtain a sufficient condition to guarantee the stability of the overall systems. This is given in [3].

However this technique solves the problem of design of decentralized of control laws which guarantee the stability of the system, it suffers from high computational effort and requirements.

In the next part, we shall offer simple algorithm to overcome the above mentioned drawbacks. The algorithm depends on decomposition coordination approach.

\section{DECENTRALIZED CONTROL STRATEGY}

In this case, the dynamic model must be represented in discrete form and it is assumed that the control structure is formed of $\mathrm{N}$ local agents, acting directly on the process [6]. Each of them (Which may present a mini or microcomputer) applies a part of control law. The process itself decomposed into subsystems, each is characterized by state $\mathrm{X}_{\mathrm{ik}}$ evolving under the control and $U_{i k}$ and interconnections $V_{i k}$ due to the other subsystems is then :

$X_{i k+1}=A_{i i} X_{i k}+B_{i i} u_{i k}+V_{i k}$

With :

$V_{i k}=\sum_{j \neq i} A_{i j} X_{j k}$

The criterion to be minimized is :

$J=\frac{1}{2} \sum_{k} \sum_{i}\left(x_{i k+1}^{T} Q_{i} x_{i k+1}+u_{i k}^{T} R_{i} u_{i k}\right.$ 
For simplicity, the matrices $Q_{i}, R_{i}$ are blockdiagonal. The part of the global criterion affected by each agent is then [6] :

$$
J=\frac{1}{2}\left[X_{i k+1}^{T^{\prime}} Q_{i} X_{i k+1}+u_{i k}^{T} R_{i} u_{i k}\right.
$$

So, the local optimization problem becories :

$$
\text { Min } C_{i k}=J_{i k}+\rho_{i k}^{T} U_{i k}
$$

Subjected to $X_{i k+1}=A_{i i} X_{i k}+B_{i i} u_{i k}+V_{i k}$. This is true $f J_{i k}$ is convex function. The local control lav is simply given by :

$$
\begin{aligned}
u_{i k} & \left.=-\left[B_{i i}{ }^{T} Q_{i} B_{i i}+R_{i i}\right]^{-1}{ }_{L} B_{i i}{ }^{T} Q_{i} A_{i i} X_{i k}+B_{i i}{ }^{T} Q V_{i k}+r_{i k}\right] \\
& =G_{i} X_{i k}+L i V_{i k}+J_{i}
\end{aligned}
$$

$\rho_{\mathrm{ik}}:$ is called the çordination vector. For more details, see $\left.\mid 6\right]$.

\section{APPLICATION OF STABILIZATION AND CONTROL STRATEGIES TO POWER SYSTEMS}

The above decentralized control and stabilizaticn techniques are apphed to an interconnected power system shown in figure (1). Each subsystem is assumed to be represented by one synchronous machine. The system model is described in the state variable form by the equations :

$$
\begin{aligned}
& \underline{X}=A \underline{X}+B \underline{u} \text { and } \\
& \underline{y}=C \underline{X}
\end{aligned}
$$

The vectors $\underline{X}, \underline{Y}$ and $\underline{U}$ are given by :

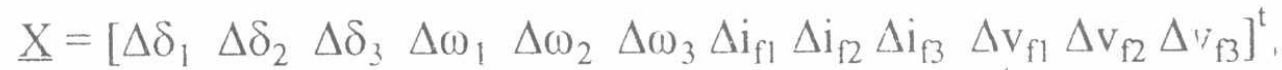

$\underline{Y}=\left[\begin{array}{lllllll}\Delta \delta_{1} & \Delta \delta_{2} & \Delta \delta_{3} & \Delta \omega_{1} & \Delta \omega_{2} & \Delta \omega_{3} \Delta v_{\mathrm{t} 1} \Delta v_{\mathrm{t} 2} \Delta \mathrm{v}_{\mathrm{t} 3}\end{array}\right]^{\mathrm{t}}$, and $\underline{u}=\left[\begin{array}{lll}u_{f 1} & u_{f 2} & u_{f 3}\end{array}\right]^{t}$.

The control $\mathrm{u}_{\mathrm{fl}}, \mathrm{u}_{\mathrm{f} 2}$, and $\mathrm{u}_{\mathrm{f} 3}$ are field regulator stabilizing signals. The disturbance is assumed as an initial perturbation of 0.02 rad ans in $\Delta \delta_{1}$. 
Several studies have to be investigated from the viewpoint of performance. Figures (2), (3), and (4) display the dynamic behavior of $\Delta \delta_{1}$, $\Delta \delta_{2}$, and $\Delta \delta_{3}$ respectively using the previous strategies given in sections (3) and (4).

The figures point to good damping and minimum steady state errors of the responses when using the proposed controllers.

\section{CONCLUSION}

The problem of stabilization and control of interconnected power systems has been considered in this paper. Two strategies are developed for constructing the required decentralized control laws. These techniques are useful for large scale power systems where the global solution is not possible either from computation or implementation view proints.

It is evident that the second technique does not require high computational requirements and also more applicable than the first technique. Moreover, the control law obtained by the first technique is quasioptional in case of cutting the links between the two levels.

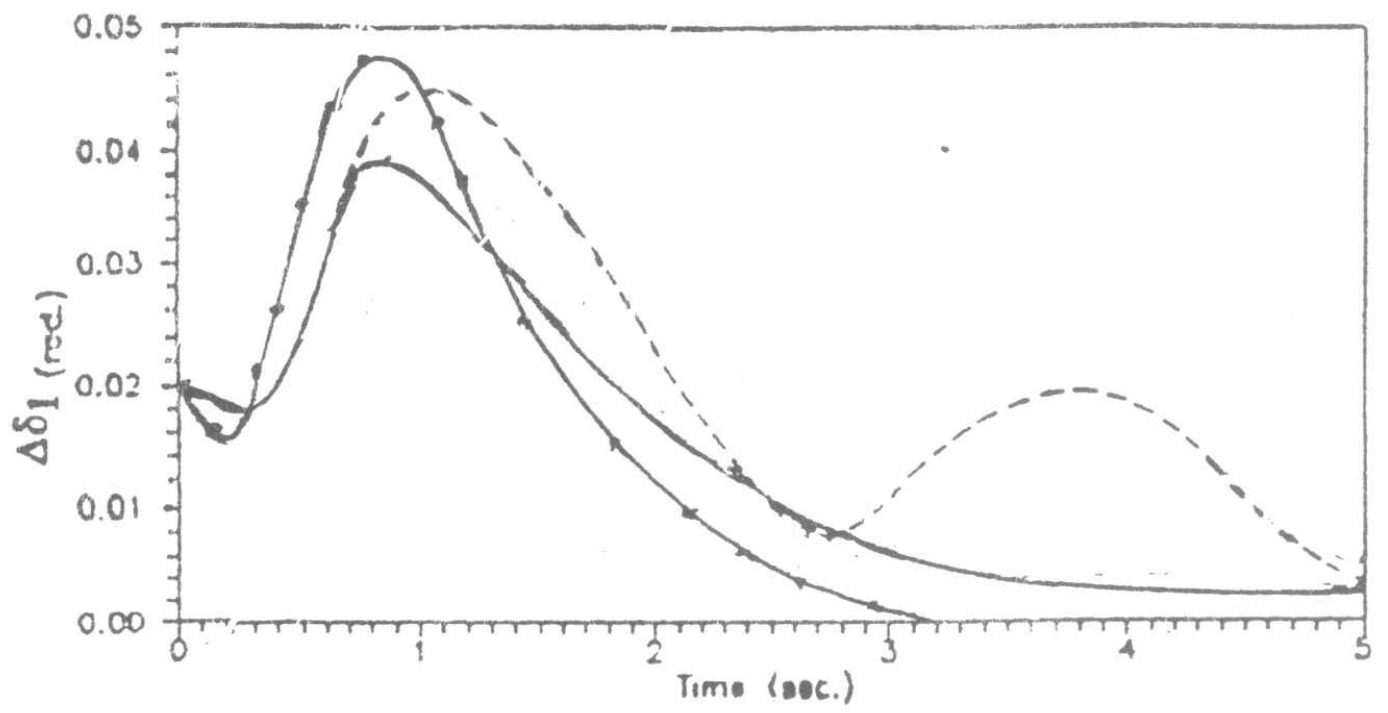

Figure (2): Dynamic response $\Delta \delta_{l}$. 


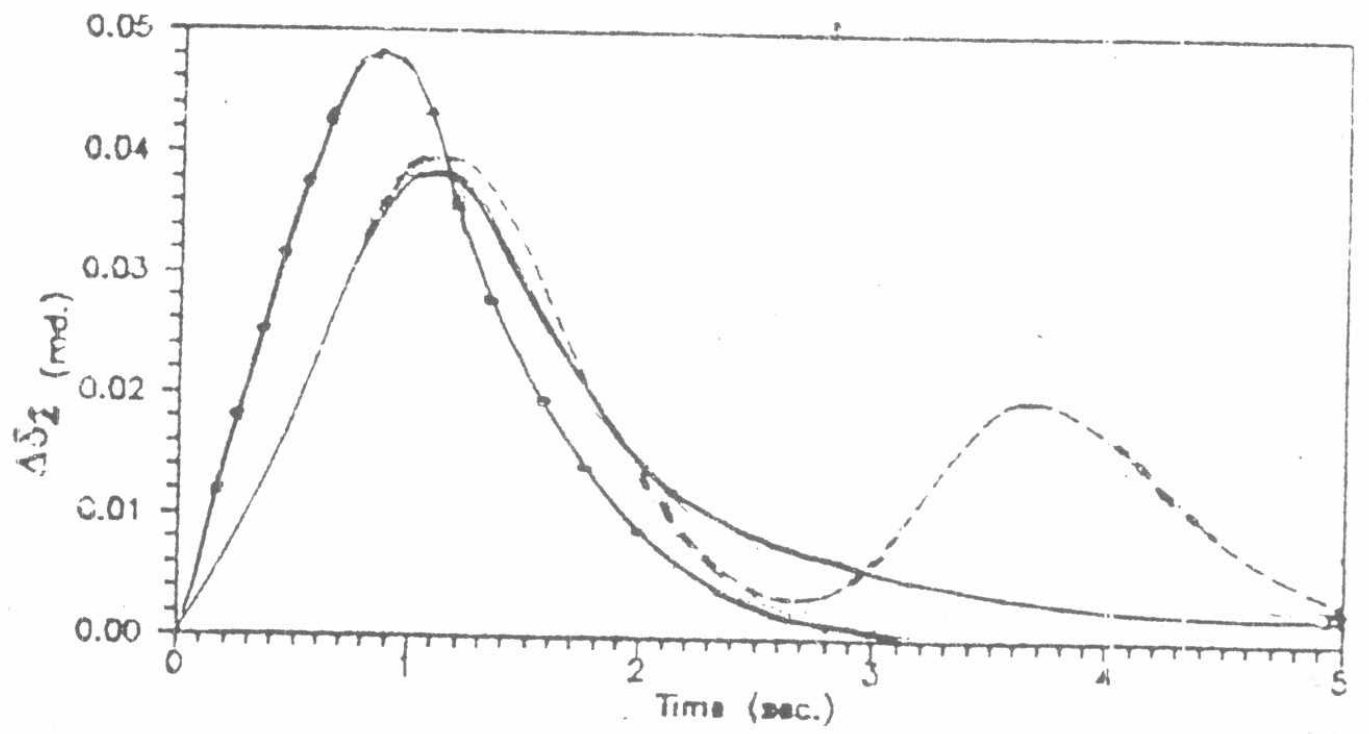

Figure (3) : Dynamic response $\Delta \delta_{2}$.

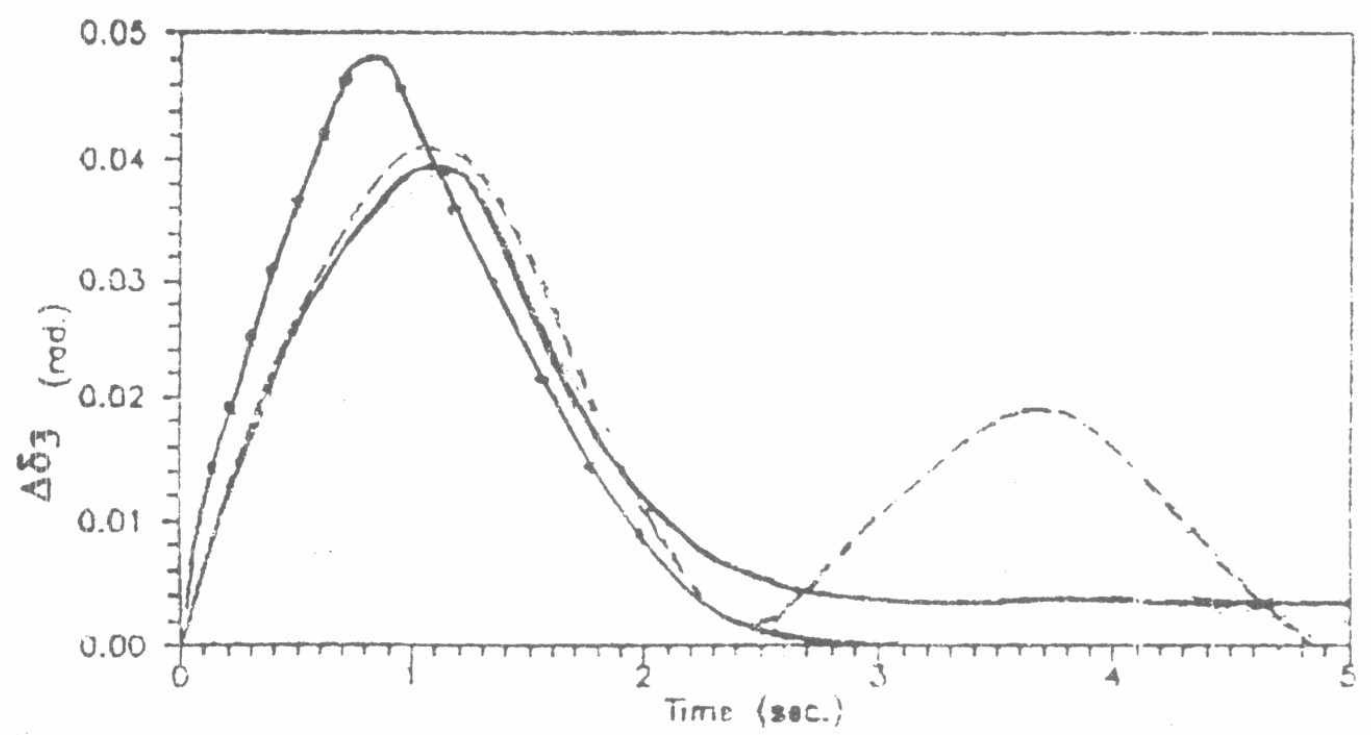

Figure (4): Dynamic response $\Delta \delta_{3}$.

-.--- Decentralized standard controller without coordination Decentralized standard controller with coordination

...... Decentralized stabilization 


\section{APPENDIX (1)}

machine parameters are :

Network and loads:

$$
\begin{array}{rlrl}
\mathrm{R}_{12} & =0.025 & \mathrm{X}_{12}=0.25 & \mathrm{R}_{13}=\mathrm{R}_{23}=0.05 \\
\mathrm{X}_{13}=\mathrm{X}_{23} & 0.5 & \mathrm{P}_{\mathrm{b} 1}=0.5 & \mathrm{Q}_{\mathrm{b} 1}=-0.2 \\
= & \mathrm{Q}_{\mathrm{b} 2}=0.3 & \mathrm{~V}_{\mathrm{D} 3}=1.0 \\
\mathrm{P}_{\mathrm{b} 2}=0.5 & \mathrm{P}_{11}=0.5 & \mathrm{Q}_{11}=0.0 \\
\mathrm{~V}_{\mathrm{Q} 3}=0.0 & \mathrm{Q}_{12}=0.5 & \mathrm{P}_{13}=1.0 \\
\mathrm{P}_{12}=0.5 & & &
\end{array}
$$

\section{Machine and regulators:}

The three machines are identical and their parameters are given by :

$$
\begin{aligned}
& X_{d}=1.2 \\
& \mathrm{X}_{\mathrm{q}}=0.8 \\
& X_{\mathrm{md}}=1.0 \\
& \mathrm{X}_{\mathrm{f}}=1.1 \\
& r_{a}=0.02 \\
& \mathrm{r}_{\mathrm{f}}=0.001 \\
& \mathrm{H}=5 \mathrm{sec} \text {. } \\
& K_{d}=0.01 \\
& \mathrm{f}=50 \mathrm{c} / \mathrm{s} \\
& \mathrm{T}_{\mathrm{e}}=0.5 \mathrm{sec} \\
& \mu_{\mathrm{e}}=1.0
\end{aligned}
$$

Note:

All quantities are in p.u. unless otherwise stated.

\section{REFERENCES}

[1] Y. N. Yu and C. Siggers, "Stabilization and optimal control signals for a power systems", IEEE Trans. PAS-90, 1971, 1469-1481.

[2] H. A. H. Moussa and Y. N. Yu, "Optimal power system stabilization through excitation and/or governor control", IEEE Trans. PAS-91, 1972, 1160-1173.

[3] H. M. Soliman and M. Darwish, "decentralized and hierarchical stabilization techriques for interconnected power systems, Large scale systems, Theory and applications", Volume 2, May 1981, 113-122.

[4] S. H. Wang, and E. J. Davison, "On the stabilization of decentralized control sys'sems", IEEE Trans. AC-18, 1973, 473-478.

[5] B. D. O. Anderson and J. B. Moore, "Linear system optimization with presr ribed degrec of stability", Proc. IEE-116(12), 1969, 2083-2087. 
[6] A. A. Abdel-Mageed, "Low sensitivity hierarchical control of power systems", Ph. D. Dissertation, University of Cairo, 1988.

[7] H. Vu, P. Pruvot, C. Launay and Y. Harmand, "An improved voltage control on large scale power system", IEEE Trans. on PAS, Aug. 1996, Vol. 11, No. 3.

[8] Q. Lu, Y. Sun, Z. Xu and T. Mochizuki, "Decentralized non linear optimal excitation", IEEE Tran. on PAS, Nov. 1996, Vol. 11, No. 4, 1957-1962.

[9] M. E. Aboul-Eía, A. A. Salem, J. D. Mo-Celley anci A. A. Fouad, "Damping controlle: design for power system oscillations using global signals", IEEE Trans. on PAS, May 1996, Vol. 11, 767-773.

10 C. M. Lim and Q. Li, "Air enhanced adaptive netia! network control

] scheme for power systems", IEEE Trans. on Energy Conversion, June 1997, Vol. 12, pp. 16()-174.

\section{Nomenclature}

i Subscript refers to subsystem No. i.

o Subscript denotes an infinite condition.

$r \quad$ Subscript denotes a reference condition.

p. u. per unit.

$\delta_{i} \quad$ Rotor angle, radians.

$\Delta \delta \quad$ Rotor angle deviation, radians.

$\Delta \omega \quad$ Angular velocity deviation, $\mathrm{rad} / \mathrm{sec}$.

$\omega_{\mathrm{o}} \quad$ Rated angular velocity, $\mathrm{rad} / \mathrm{sec}$.

$\mathrm{V}_{\mathrm{ti}} \quad$ Magnitude of machine terminal voltage.

$\mathrm{P}_{\mathrm{ti}} \quad$ Active power output of the machine.

$\mathrm{Q}_{\mathrm{ti}} \quad$ Reactive power output of the machine.

$\mathrm{O}_{\mathrm{b}_{1}}, \mathrm{Q}_{\mathrm{bi}} \quad$ Active and reactive power at network bus.

$\mathrm{P}_{\mathrm{li}}, \mathrm{Q}_{\mathrm{li}} \quad$ Active and reactive power of a load. 